\title{
Qualidade da carne de cordeiros castrados e não-castrados confinados sob dois fotoperíodos
}

\author{
Manoel Henrique Klein Júnior ${ }^{1}$, Edson Ramos de Siqueira ${ }^{2}$, Roberto de Oliveira Roça ${ }^{3}$ \\ ${ }^{1}$ Centro de Ciências Agrárias, Departamento de Morfofisiologia Veterinária, Universidade Federal do Piauí, Campus da Socopo, Teresina, \\ PI, CEP: 64.049550 \\ ${ }^{2}$ Faculdade de Medicina Veterinária e Zootecnia, UNESP, Botucatu, Departamento de Produção e Exploração Animal. \\ ${ }^{3}$ Faculdade de Ciências Agronômicas, UNESP, Botucatu, Departamento de Gestão Agroindustrial.
}

\begin{abstract}
RESUMO - Objetivou-se avaliar a qualidade da carne por meio da determinação da composição centesimal e das características físicas da paleta e do lombo de 20 cordeiros mestiços Ideal, não-castrados (NC) e castrados (C), submetidos a fotoperíodos curto, de 12 horas (FC), e longo, de 18 horas (FL). Os animais foram divididos ao acaso em esquema fatorial 2 × 2 (condição sexual x fotoperíodo), em quatro tratamentos ( $\mathrm{NC}$ em FC; C em FC; NC em FL; e C em FL), com cinco repetições, sendo terminados em confinamento individual até que atingissem $37 \mathrm{~kg}$ de PV. A qualidade da carne foi determinada em amostras da paleta e do músculo Longissimus lumborum (LL). Os mais baixos teores de umidade e os mais altos de EE, tanto na paleta como no lombo, foram determinados na carne dos animais castrados. O fotoperíodo longo influenciou significativamente os teores de EE e proteína total do músculo LL. A capacidade de retenção de água foi afetada pelo FL, no qual foram encontrados percentuais mais baixos. Não houve efeito do fotoperíodo nem da condição sexual sobre a capacidade de absorção de água e a perda de peso por cozimento do músculo LL. Os valores de força de cisalhamento (FoCi) na carne de cordeiros NC e dos submetidos ao FL foram superiores aos da carne dos animais castrados ou expostos ao FC.
\end{abstract}

Palavras-chave: castração, luminosidade, ovino, propriedades da carne

\section{Meat quality of feedlot castrated or intact male lambs exposed to two photoperiod lengths}

\begin{abstract}
The objective of this study was to evaluate muscle composition and physical-chemical characteristics of 20 intact and castrated crossbred Ideal male lambs exposed to either a short photoperiod (SP) of $12 \mathrm{~h}$ or to a long photoperiod (LP) of $18 \mathrm{~h}$. Animals were randomly assigned to four treatments (T) in a 2 × 2 factorial arrangement with five repetitions as follows: intact lambs exposed to a SP; castrated lambs exposed to a SP; intact lambs exposed to a LP or castrated lambs exposed to a LP. Animals were maintained in individual pens until they reached $37 \mathrm{~kg}$ of body weight. Meat quality was determined in meat samples from the blade and from the Longissimus lumborum muscle (loin). The lowest contents of moisture and the greatest contents of fat in both the blade and loin were observed on the meat of castrated lambs. The LP significantly affected the contents of fat and protein of the loin. The water-holding capacity of the loin was lowest when animals were exposed to a LP while no significant differences were observed for water-biding capacity and cooking losses. Meat from intact lambs had significantly higher shear force (SF) than from that of castrated lambs. In addition, exposition to a LP also significantly increased the SF compared to SP exposition.
\end{abstract}

Key Words: castration, lamb, meat quality, photoperiod

\section{Introdução}

A ovinocultura no estado de São Paulo tem como prioridade a produção de carne (Siqueira, 2000). Contudo, o desmame precoce e o confinamento total dos cordeiros até atingirem o peso de abate tem sido recomendados (Siqueira et al., 1993), pois a parasitose (Amarante, 2002) limita a criação em pastagens. Existem várias possibilidades de manipulação do sistema de produção em confinamento que permitem a obtenção, de forma rápida, de carcaça e carne ovina de elevada qualidade para abastecimento do mercado com produto diferenciado. Nesse sentido, medidas alternativas devem ser testadas para melhorar o desempenho, a qualidade da carcaça e a carne dos animais confinados. Entre essas opções, está a manipulação do fotoperíodo, aliado ou não à castração.

Além dos aspectos reprodutivos influenciados pela luminosidade (Fitzgerald et al., 1983; Malpaux et al., 1996), verificam-se em fêmeas e machos efeitos desse fator no desenvolvimento corporal dos animais a partir do uso da 
iluminação artificial no confinamento. Quantidade mais elevada de gordura na carcaça (Forbes et al., 1979) e velocidade superior no ganho de peso, associadas ao maior consumo de alimentos (Schanbacher, 1984; Barenton et al., 1988; Montenegro \& Siqueira, 2001), são as principais variáveis afetadas pela maior exposição à luz. No entanto, ausência de efeito do fotoperíodo no desempenho e nas características de carcaça tem sido relatada na literatura (Carvalho, 2002; Sá et al., 2005).

Outro aspecto que repercute na produtividade animal é a condição sexual. A castração é uma técnica utilizada em algumas regiões na terminação de cordeiros. Embora a maioria dos efeitos desejáveis, relacionados a teores de gordura mais baixos, no desenvolvimento dos animais e nas características de carcaça tenha sido verificada em animais não-castrados (Schanbacher \& Crouse, 1980; Crouse et al., 1981; Lloyd et al., 1981; Kelestimur, 1985; Osório et al., 1999; Carvalho et al., 1999), cordeiros castrados podem apresentar quantidades baixas de gordura na carcaça. Algumas variáveis obtidas na carcaça revelam não haver diferenças quando comparadas a animais nãocastrados ou fêmeas (Abdullah et al., 1994; Carvalho et al., 1997; Ribeiro et al., 1998).

A aceitação da carne pelo consumidor pode ser afetada de forma negativa ou positiva, tanto do ponto de vista nutricional como em relação às qualidades físicas (Sañudo, 2001). Para avaliar a qualidade da carne ovina, é necessário determinar várias características, destacando-se a composição centesimal, a capacidade de retenção e absorção de água e a maciez (Lemos Neto, 1997; Hoffman et al., 2003).

Diante do exposto, o objetivo neste trabalho foi investigar a qualidade da carne de cordeiros terminados em confinamento submetidos à manipulação do fotoperíodo, aliado ou não à castração.

\section{Material e Métodos}

Vinte cordeiros mestiços com predominância da raça Ideal, desmamados aos 70 dias de idade, foram terminados em confinamento individual sob dois fotoperíodos. Aos 90 dias, dez destes animais foram castrados cirurgicamente por meio da retirada dos testículos. O período de recuperação foi de três semanas e o pós-período (de adaptação), de 15 dias, quando receberam dieta balanceada, à vontade, e fotoperíodo de 12 horas de luz, em ambos os grupos. O experimento teve início em fevereiro e término em maio. Os animais foram distribuídos nas baias, dispostas em duas salas isoladas entre si, onde foram aplicados dois fotoperíodos: 12 horas de luz - cinco cordeiros não-castrados e cinco castrados; 18 horas de luz - cinco cordeiros nãocastrados e cinco castrados. O horário da iluminação foi regulado por um temporizador, ligado às $6 \mathrm{~h}$ em ambas as salas e desligado às $24 \mathrm{~h}$ (tratamentos com 18 horas de fotoperíodo) e às $18 \mathrm{~h}$ (tratamentos com 12 horas de fotoperíodo). Em cada sala, foram utilizadas quatro lâmpadas fluorescentes, com intensidade lumínica total de 300 lux.

Os animais receberam dieta balanceada, à vontade, calculada para ganho médio de peso diário de $0,300 \mathrm{~kg}$ (NRC, 1985), composta por concentrado e volumoso na proporção de 75:25. Os animais com $37 \mathrm{~kg}$ PV e 6 a 7 meses de idade foram abatidos após jejum e dieta hídrica de 18 horas. Os animais foram abatidos em matadouro privado, com inspeção veterinária estadual, localizado a $20 \mathrm{~km}$ do local de terminação dos animais. Após a pesagem, as carcaças foram transferidas para câmara frigorífica a $4^{\circ} \mathrm{C}$, por aproximadamente 24 horas, para a divisão em meia-carcaças e obtenção dos cortes segundo a técnica de ColomerRocher \& Espejo (1972). Os cortes comerciais paleta e lombo, obtidos em cada meia-carcaça (20 de cada corte), foram identificados, acondicionados em sacos de polietileno e armazenados em freezer a $-18^{\circ} \mathrm{C}$. Os cortes foram mantidos sob refrigeração (entre 5 a $8^{\circ} \mathrm{C}$ ) por cerca de 14 horas e dissecados à temperatura ambiente controlada de $25^{\circ} \mathrm{C}$.

As análises do lombo foram realizadas no músculo Longissimus lumborum (LL) na porção correspondente às bases ósseas entre a $13^{\mathrm{a}}$ vértebra torácica e a $1^{\mathrm{a}}$ vértebra sacral. Após descongelamento sob refrigeração (entre $5 \mathrm{e}$ $8^{\circ} \mathrm{C}$ ) por cerca de 24 horas, o músculo LL foi dividido transversalmente em três partes conforme as diferentes determinações. A parte caudal foi cortada com $5 \mathrm{~cm}$ de comprimento, desprezando-se $2 \mathrm{~cm}$ do final. Na fração com os $3 \mathrm{~cm}$ restantes, foi feita uma nova divisão, obtendo-se dois cortes consecutivos (A e B) com mesma espessura para a avaliação da perda por cozimento e maciez. O restante do músculo LL, iniciado na região equivalente a $13^{\mathrm{a}}$ vértebra torácica até o local do primeiro corte, foi dividido ao meio para as demais avaliações. A parte medial foi utilizada para determinação da capacidade de retenção de água (CRA) e da capacidade de absorção de água (CAA). A parte cranial restante foi utilizada para análise da composição química. Para a paleta, todos os músculos dissecados de cada peça foram triturados, homogeneizados, constituindo uma massa muscular utilizada nas análises físico-químicas.

A composição centesimal da porção muscular magra dos músculos da paleta e domúsculo LL envolveu o cálculo dos teores de umidade, resíduo mineral fixo (RMF), proteína total e EE, de acordo com a metodologia da AOAC (1990). 
Para análise da umidade, adotou-se o método de secagem em estufa a $105^{\circ} \mathrm{C}$ até peso constante. O RMF foi determinado pelo método de incineração em mufla a $550-600^{\circ} \mathrm{C}$ até peso constante. Para determinação da proteína total, utilizou-se a metodologia baseada na avaliação do nitrogênio total, feita pelo processo de digestão micro Kjeldahl utilizando-se 6,25 como fator de conversão. O EE foi determinado por extração da gordura por lavagem com éter de petróleo, seguida pela destilação e conseqüente evaporação do solvente em aparelho de Soxhlet.

As análises da capacidade de retenção de água (CRA) e de absorção de água (CAA) foram feitas conforme técnica desenvolvida por Roça (1986) por meio de centrifugação e pesagem das amostras. Foram utilizadas a parte medial das amostras do músculo LL cortado para esta finalidade, no momento das determinações, e os resultados foram expressos em porcentagem.

A perda por cozimento (PPC) foi determinada nos cortes consecutivos A e B do músculo LL $(1,5 \mathrm{~cm}$ de espessura), obtidos a $2 \mathrm{~cm}$ do final da musculatura. Cada amostra foi pesada em balança analítica e, em seguida, foi acondicionada em saco plástico resistente a banho-maria a $90^{\circ} \mathrm{C}$. Durante a imersão, os sacos de polietileno contendo as amostras foram pendurados de forma a não permitir a entrada de água (Honikel, 1998). Após banho-maria a $75^{\circ} \mathrm{C}$ durante 1 hora, as amostras foram retiradas, acondicionadas, resfriadas em água fria, removidas da embalagem, secas em papel-toalha e novamente pesadas. A perda por cozimento foi calculada como a diferença de peso da amostra antes e depois do cozimento, expressa como porcentagem do peso inicial da amostra.

A maciez foi determinada nas mesmas amostras do músculo LL utilizadas na determinação da perda por cozimento, uma hora após esta análise, conforme Honikel (1998). Foram aleatoriamente removidos cilindros de cada uma das duas amostras de músculo (cortes A e B) no sentido da fibra com a utilização de uma furadeira acoplada a uma sonda vazada de 1,27 $\mathrm{cm}$ de diâmetro. A maciez foi avaliada instrumentalmente pela técnica da força de cisalhamento com a utilização de um texturômetro Salter, equipado com célula de carne Warner-Bratzler, padrão "stable micro system". Na avaliação, utilizou-se a velocidade de cisalhamento de $20 \mathrm{~cm} /$ segundo. Foi calculada a média dos cilindros para os dois bifes em cada músculo e os resultados foram expressos em quilogramas. Quanto menor a força empregada, mais macia foi considerada a carne.

Foi utilizada a análise de variância em esquema fatorial $2 \times 2$, conforme Snedecor \& Cochran (1989), para estimativa dos efeitos do fotoperíodo (longo e curto), da condição sexual (inteiro e castrado) e da interação fotoperíodo $\times$ condição sexual dos animais sobre as diversas variáveis da composição física e química. Para os cálculos estatísticos, foi empregado o procedimento modelo linear geral (GLM) do programa SAS, versão 6 (1989). No caso de F significativo, as médias foram comparadas pelo teste Tukey a $5 \%$ de significância.

\section{Resultados e Discussão}

Os teores de umidade, RMF, proteína total e EE dos músculos da paleta e do músculo LL do lombo são apresentados nas Tabelas 1 e 2 . Não foi evidenciado efeito de interação fotoperíodo $\times$ condição sexual. Houve efeito da condição sexual sobre a umidade e o teor de $\mathrm{EE}(\mathrm{P}<0,01)$ nos dois cortes estudados. Nos músculos da paleta e no músculo LL, os teores de umidade para os animais castrados (70,35 e 70,39\%) foram maiores que para os não-castrados (72,10 e 71,96\%), assim como os percentuais de EE, que foram maiores na carne dos castrados $(7,96$ e 6,78\%) e menores na dos não-castrados (6,20 e 5,51\%). Não houve diferença em relação às porcentagens do RMF e a proteína total. Por outro lado, o fotoperíodo teve efeito sobre o EE e a proteína total do músculo LL, de modo que os cordeiros submetidos a maior exposição a luz apresentaram mais gordura intramuscular $(6,42)$ que os do $\mathrm{FC}(5,87 \%)$, independentemente da condição sexual. Apesar da significância, a diferença para proteína total foi pequena $(20,38 \%$ para FC e 20,72\% para FL).

Em cordeiros das raças Hampshire Down e Santa Inês terminados em confinamento abatidos com $31 \mathrm{~kg}$ de PV expostos a 18 horas de luz, a composição centesimal do músculo LL, não foi influenciada pelo fotoperíodo ou pelo genótipo sobre sendo verificada média superior para umidade $(75,46 \%)$ e inferior para o EE $(2,2 \%)$ e similar para o RMF e a proteína total (Sá et al., 2005). Além do efeito raça, o peso de abate mais elevado $(37 \mathrm{~kg})$ neste estudo deve ter influenciado essas diferenças. Contudo, Macedo (1998) relatou que cordeiros Corriedale, Bergamacia x Corriedale e Hampshire Down x Corriedale confinados e abatidos com 30-32 kg de PV apresentaram percentual de EE bem superior $(11,54 \%)$. Estes dados demonstram que a porcentagem de gordura intramuscular é a que mais varia em função da área muscular analisada, do sexo, do peso de abate e dos níveis nutricionais (Sarti et al., 1993). É possível verificar variações muito expressivas para esta variável nos diferentes tratamentos efetuados (Lemos Neto, 1997; Rowe, 1998; Garcia \& Silva Sobrinho, 1998; Garcia et al., 1999; Prado, 1999), alcançando valores que variam de 2,0 (Garcia et al., 1999) a 17,24\% (Cañeque et al., 1989), embora nem sempre difiram entre a condição sexual (Dransfield et al., 1990). A 
Tabela 1 - Composição físico-química da porção muscular magra da paleta de cordeiros castrados e não-castrados confinados sob dois fotoperíodos

Table 1 - Physical-chemical composition of blade lean portion of intact and castrated feedlot male lambs exposed to two photoperiod lengths

\begin{tabular}{|c|c|c|c|}
\hline \multirow{3}{*}{ Condição sexual } & \multicolumn{2}{|c|}{$\begin{array}{c}\text { Fotoperíodo } \\
\text { Photoperiod }\end{array}$} & \multirow[t]{3}{*}{$\begin{array}{l}\text { Média } \\
\text { Mean }\end{array}$} \\
\hline & Curto & Longo & \\
\hline & Short & Long & \\
\hline
\end{tabular}

\begin{tabular}{c}
\hline Paleta \\
Shoulder \\
\hline
\end{tabular}

\begin{tabular}{lcccc}
\hline \multicolumn{4}{c}{$\begin{array}{c}\text { Umidade (\%) } \\
\text { Moisture (\%) }\end{array}$} \\
\hline $\begin{array}{l}\text { Não-castrados } \\
\text { Intact }\end{array}$ & 71,42 & & 72,97 & $72,19 \mathrm{~A}^{2}$ \\
$\begin{array}{l}\text { Castrados } \\
\text { Castrated }\end{array}$ & 70,74 & & 69,96 & $70,35 \mathrm{~B}$ \\
$\begin{array}{l}\text { Média } \\
\text { Mean }\end{array}$ & 71,08 & & 71,46 & \\
$\mathrm{CV}(\%)^{1}$ & & & & \\
\hline
\end{tabular}

Resíduo mineral fixo (\%)

Ash (\%)

\begin{tabular}{lccc}
\hline $\begin{array}{l}\text { Não-castrados } \\
\text { Intact }\end{array}$ & 1,04 & 1,03 & 1,03 \\
$\begin{array}{l}\text { Castrados } \\
\text { Castrate }\end{array}$ & 1,02 & 1,05 & 1,03 \\
$\begin{array}{l}\text { Média } \\
\text { Mean }\end{array}$ & 1,03 & & 1,04 \\
CV $(\%)$ & & & \\
\hline
\end{tabular}

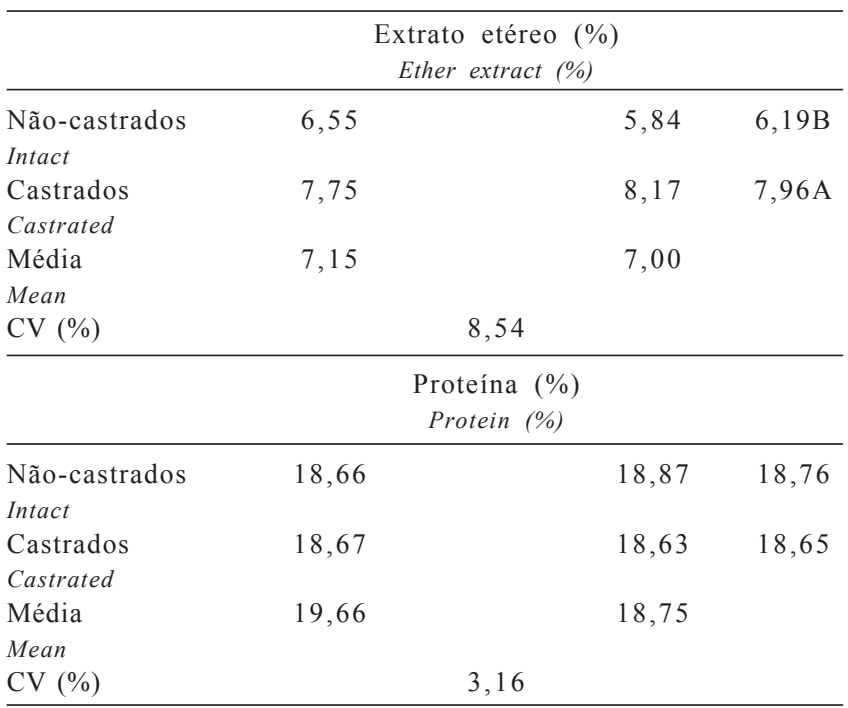

${ }^{1}$ Coeficiente de variação.

2 Médias seguidas de letras diferentes na mesma coluna indicam diferença $(\mathrm{P}<0,05)$ pelo teste Tukey.

1 Coeficient of variation.

${ }^{2}$ Means with different letters within the same column differ $(P<0.05)$ by Tukey test.

análise da composição centesimal permite conhecer o valor nutritivo da carne (Price \& Schweigert, 1976) e, portanto, é possível considerar que a carne magra se enquadrou nos limites aceitáveis e a castração, apesar de ter influenciado no aumento da gordura, não prejudicou a comercialização (Santos et al., 2002, 2003). O efeito da castração sobre o EE
Tabela 2 - Composição físico-química do músculo Longissimus lumborum de cordeiros castrados e não-castrados confinados sob dois fotoperíodos

Table 2 - Physical-chemical composition of Longissimus lumborum muscle of intact and castrated feedlot male lambs exposed to two photoperiod lengths

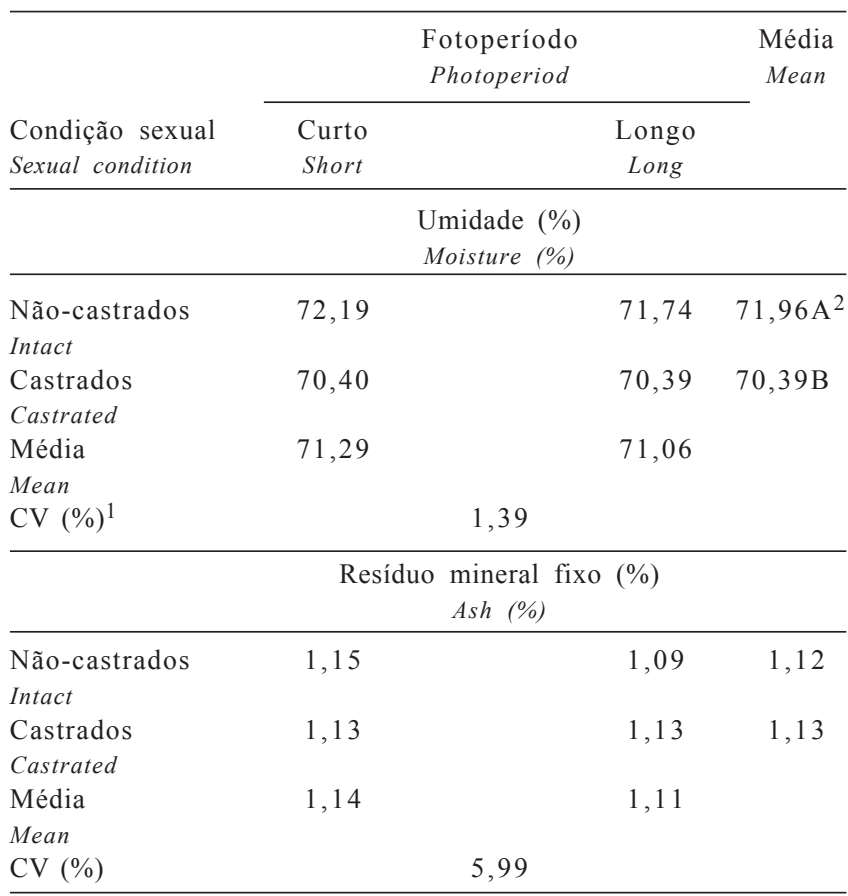

CV $(\%)$

Extrato etéreo (\%) Ether extract (\%)

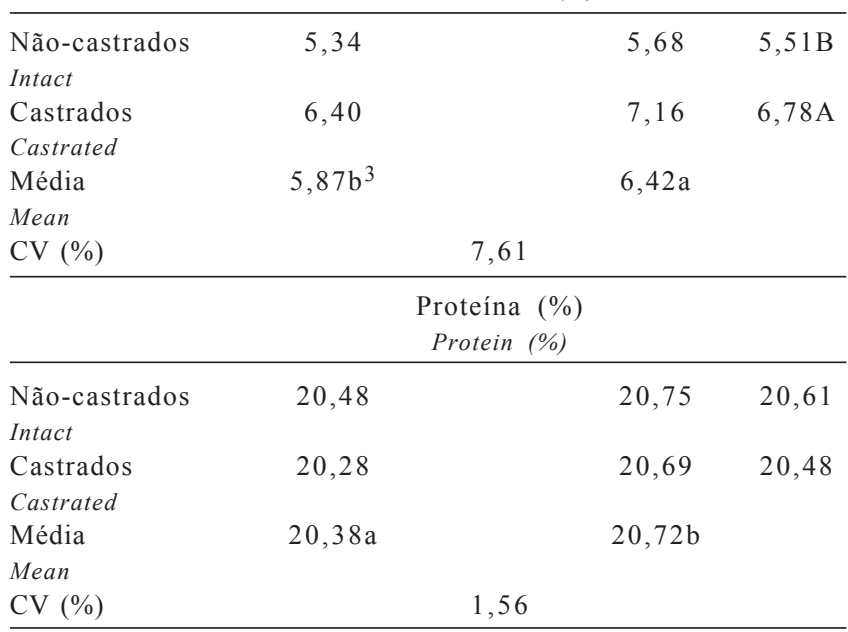

${ }^{1}$ Coeficiente de variação.

2 Médias seguidas de letras diferentes na mesma coluna indicam diferença $(P<0,05)$ pelo teste Tukey.

3 Médias seguidas de letras minúsculas diferentes na mesma linha diferem $(P<0,05)$ pelo teste Tukey.

1 Coeficient of variation.

2 Means with different letters within the same column differ $(P<0.05)$ by Tukey test.

${ }^{3}$ Means with different small letters within the same row differ $(P<0.05)$ by Tukey test.

era esperado, principalmente quando da avaliação da gordura de cobertura (Schanbacher \& Crouse, 1980; Crouse et al., 1981; Lloyd et al., 1981; Kelestimur, 1985; Osório et al., 1999; Carvalho et al., 1999).

A comparação da quantidade de tecido adiposo e da concentração de lipídios no músculo LL de cordeiros castra- 
dos, não-castrados e criptorquídicos revelou densidade de gordura de cobertura e intramuscular inferior nos machos não-castrados $(0,26 \mathrm{~cm} \mathrm{e} 3,8 \%)$ em relação aos castrados $(0,56 \mathrm{~cm} \mathrm{e} 4,9 \%)$, embora sem diferença estatística (Solomon et al., 1990).

Os resultados das médias e dos coeficientes de variação da CRA, CAA, PPC e da força de cisalhamento (FoCi) do músculo LL estão apresentados na Tabela 3. De forma interessante, o FL afetou a CRA, resultando em percentuais mais baixos desta variável, independentemente da condição sexual, embora os castrados tenham apresentado valor médio mais elevado que os não-castrados. Considerando o valor da CRA como uma característica importante da propriedade da carne, poderse-ia aceitar o fato de que os animais não-castrados submetidos ao FL produziram carnes de qualidade inferior, em razão da menor capacidade de retenção de líquidos, resultando em carne mais seca e com menor maciez (Silva Sobrinho, 2001).

Utilizando método de centrifugação desenvolvido por Roça (1986), os valores da CRA de 49,28 e 50,65\% obtidos por Lemos Neto (1997) foram semelhantes para os genótipos Corriedale e Ile de France x Corriedale, respectivamente. Este resultado permitiu enquadrar a carne como aceitável, visto que, na análise sensorial, as amostras receberam notas de 5 a 6 (nem seco, nem suculento). Para a mesma variável, Alberti \& Sañudo (1988) encontraram variações bem menores (de 17,0 a $21,4 \%$ ) e Sañudo et al. (1992) obtiveram percentuais de 22; 96; 25,30 e 22,62 para as raças Rasa Aragonesa, Ojinegra de Teruel e cruzamento de Fleischschaf x Rasa, respectivamente. Apesar de mais elevados que os resultados obtidos por Lemos Neto (1997), foram mais próximos daqueles relatados por Alberti \& Sañudo (1988) e Sañudo et al. (1992), provavelmente pelo uso da mesma técnica de avaliação, conforme advertiu Lemos Neto (1997) quanto aos cuidados na comparação entre diferentes trabalhos. Deve-se ainda ressaltar que o desenvolvimento do rigor mortis e a velocidade e extensão do declínio de $\mathrm{pH}$, juntamente com o processo de congelamento das amostras, podem também ter influenciado nas variações dos valores observados entre esses estudos (Felício, 1999).

Quanto à CAA, não foram observados efeitos do fotoperíodo e da condição sexual (Tabela 3), embora os animais castrados tenham apresentado maior percentual, provavelmente em razão da maior quantidade de gordura intramuscular. Embora a CAA possa ter importância na industrialização da carne, não foi possível constatar, na literatura consultada, outros trabalhos utilizando a carne ovina para determinação desta variável.
Não houve efeito do fotoperíodo ou da condição sexual sobre a PPC do músculo LL (Tabela 3). Para melhor entendimento da técnica utilizada (Honikel, 1998), apesar de as amostras possuírem mesma espessura (os bifes seriam utilizados para determinação da maciez), apresentaram pesos bastante diferentes (dados não apresentados), tendo em vista a localização das amostras no músculo LL, possuindo assim áreas distintas. Contudo, além de não terem sido verificadas diferenças entre os cortes, os percentuais obtidos foram muito próximos, o que pode indicar que o cozimento (temperatura ou tempo) não foi adequado ou que a variação realmente não ocorreu porque os cortes foram feitos em seqüência. Cañeque et al. (2004) avaliaram a PPC submergindo as amostras por tempo inferior ( 15 minutos) ao utilizado nesta pesquisa e obtiveram percentual médio menor $(26,04 \%)$, embora tenham utilizado cordeiros em amamentação com 8 a $10 \mathrm{~kg}$ de PV.

Segundo Felício (1999) esta técnica provoca a desnaturação das proteínas com liberação de água extra e intracelular e é indicada para elaboração de carnes précozidas. Diferenças na PCC entre os músculos Biceps femoris e LD foram relatadas por Pérez et al. (1997), que associaram o menor valor obtido no músculo LL à sua maior maciez. Contudo, deve-se ressaltar que, neste experimento, foi utilizada outra forma de cozimento dos bifes. Hoffman et al. (2003), no entanto, utilizando a técnica de Honikel (1998), não obtiveram diferenças significativas no músculo LL de seis genótipos, apesar da grande variação dos resultados (17,76 a 23,04\%). Estes resultados, inferiores aos deste estudo, podem ser atribuídos à utilização de animais com aptidão para carne, criados em pastagem e abatidos aos $40 \mathrm{~kg}$.

Verificou-se que a carne dos cordeiros submetidos ao FL apresentou FoCi (4,92 kgf) maior que a dos animais expostos ao FC (3,80 kgf). Na carne dos animais castrados, obteve-se força de $3,11 \mathrm{kgf}$, inferior à encontrada na carne dos não-castrados (5,62 kgf). Cordeiros submetidos ao FL tiveram melhores desempenhos relativos ao crescimento (Schanbacher \& Crouse, 1980; Schanbacher, 1984; Barenton et al., 1988; Montenegro \& Siqueira, 2001), contudo, esses efeitos não foram identificados nestes animais (Carvalho, 2002a e 2002b), dificultando explicar o efeito do FL na obtenção de uma carne menos macia.

$\mathrm{Na}$ técnica FoCi, considera-se para análise dos resultados o limite de 4,6 kgf entre carne macia $(<4,6 \mathrm{kgf})$ e dura (>4,6 kgf) proposto por Shackelford et al. (1991), citado por Felício (1999). Embora a FoCi esteja padronizada para bovinos, diversos pesquisadores têm realizado adaptações da técnica, principalmente na etapa do cozimento, 
Tabela 3 - Capacidades de retenção (CRA) e absorção de água (CAA), perda de peso no cozimento (PPC) e força de cisalhamento ( $\mathrm{FoCi}$ ) do músculo Longissimus lumborum de cordeiros castrados e não-castrados confinados sob dois fotoperíodos

Table 3 - Water hold capacity (WHC), water-biding capacity (WBC), cooking loss (CL) and shearforce of the Longissimus lumborum muscle of intact and castrated feedlot male lambs exposed to two photoperiod lengths

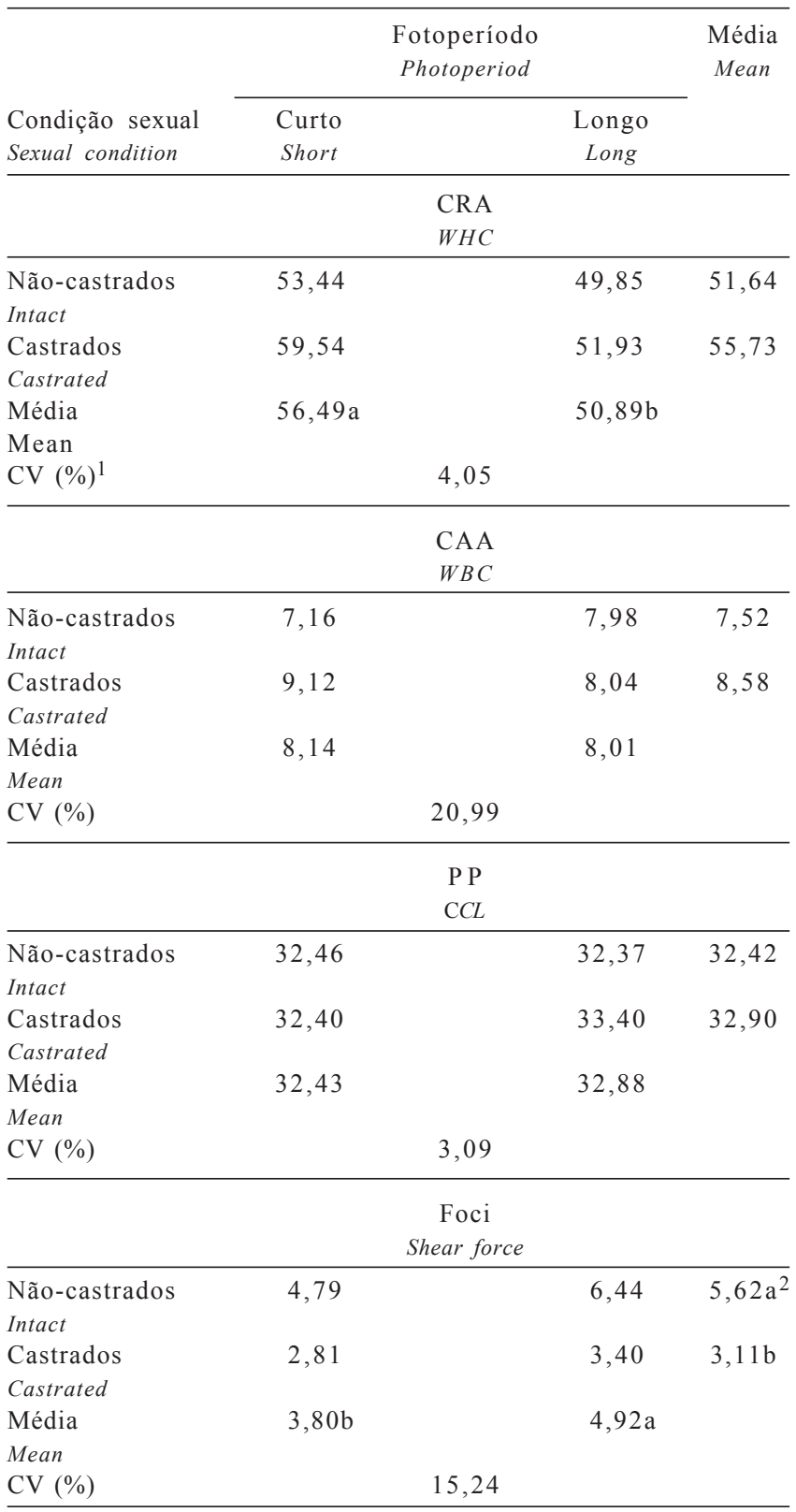

${ }^{1}$ Coeficiente de variação.

2 Médias seguidas de letras diferentes na mesma coluna indicam diferença $(\mathrm{P}<0,05)$ pelo teste Tukey.

1 Coeficient of variation.

2 Means with different letters within the same column differ $(P<0.05)$ by Tukey test.

para determinação das características da carne no músculo LL de ovinos (Voisey, 1976; Honikel, 1998). Assim, Hoffman et al. (2003), utilizando a mesma técnica adotada nesta pesquisa, constataram efeito para o genótipo, mas com grande variação entre as raças $(6,7$ a 10,7 kgf) e superiores aos dados obtidos neste estudo. Cañeque et al. (2004) compararam a FoCi do músculo LL cru e cozido $\left(15\right.$ minutos em banho-maria a $\left.75^{\circ} \mathrm{C}\right)$ e constataram valores bem inferiores (2,39 e 1,76 kgf, respectivamente), porém utilizaram cordeiros em amamentação com 8 a $10 \mathrm{~kg}$ de PV.

\section{Conclusões}

O fotoperíodo longo teve efeito sobre os teores de EE e proteína total do músculo Longissimus lumborum promovendo maiores percentuais nestas duas variáveis. Tanto a paleta como o lombo dos cordeiros castrados apresentaram teores menores de umidade e maiores de extrato etéreo.

O fotoperíodo longo proporcionou carnes com menor capacidade de retenção de água.

A capacidade de absorção de água e a perda por cozimento não foram influenciadas pelo fotoperíodo e pela condição sexual. Cordeiros castrados apresentaram carne mais macia.

\section{Literatura Citada}

ABDULLAH, F.M.; SALLEH, R.M.; KHUSAHRY, M.Y.M. et al. Body components and carcass characteristics of induced cryptorchids, wethers and intact males. In: ANIMAL SCIENCE CONGRESS, 7., 1994, Bali. Proceedings... Bali: Australian Association of Animal Production, 1994. p.69.

ALBERTI, P.; SAÑUDO, C. Caracteristicas de la canal y calidad de la came de terneros cebados com dietas forrajeras y suplementados com distinta cantidad de pienso. Revista ITEA, n.76, p.3-14, 1988 .

AMARANTE, A.F.T. Avanços no controle da verminose ovina. In: SIMPÓSIO PAULISTA DE OVINOCULTURA, 6., 2002, Botucatu. Anais... Botucatu: Faculdade de Medicina Veterinária e Zootecnia - UNESP, 2002. p.59-74.

ASSOCIATION OF OFFICIAL ANALITICAL CHEMISTS - AOAC. Official methods of analysis. 15.ed. Arlington: Association of Analytical Chemists, 1990. 1158p.

BARENTON, B.; RAVAUT, J.P.; CHABANET, C. et al. Photoperiodic control of growth hormone, secretion and body weight in rams. Domestical Animal Endocrinology, v.5, n.3, p.247-255, 1988 .

CAÑEQUE, V.; HUILDOBRO, F.R.; DOLZ, J.F. et al. Producción de carne de cordero. Madrid: Ministério de Agricultura Pesca y Alimentación, 1989. 520p.

CAÑEQUE, V.; PEREZ, C.; VELASCO, S. et al. Carcass and meat quality of light lambs using principal component analysis. Meat Science, v.67, n.1, p.595-605, 2004.

CARVALHO, S.; PIRES, C.C.; PERES, J.R.R. et al. Performance of whole males lambs, castrated males lambs and females lambs, feed in confinement. Ciência Rural, v.29, n.1, p.129-133, 1999.

CARVALHO, S.; PIRES, C.C.; SACCOL, A.G. et al. Confinamento de cordeiros machos não castrados, castrados e fêmeas abatidos aos 100 dias de idade. In: REUNIÃO ANUAL DA SOCIEDADE BRASILEIRA DE ZOOTECNIA, 34., 1997, Juiz de Fora. Anais... Juiz de Fora: Sociedade Brasileira de Zootecnia, 1997. p. 378 .

CARVALHO, S.R.S.T.; SIQUEIRA, E.R.; BIASIN, M.F. et al. Desempenho e características da carcaça de cordeiros não 
castrados e castrados, submetidos a dois fotoperíodos In: REUNIÃO ANUAL DA SOCIEDADE BRASILEIRA DE ZOOTECNIA, 39., 2002, Recife. Anais... Recife: Sociedade Brasileira de Zootecnia, 2002a. p.241-243.

CARVALHO, S.R.S.T.; SIQUEIRA, E.R.; BIASIN, M.F. et al. Avaliação morfométrica, cortes das carcaças e composição tecidual do lombo de cordeiros não castrados e castrados, submetidos a dois fotoperíodos. In: REUNIÃO ANUAL DA SOCIEDADE BRASILEIRA DE ZOOTECNIA, 39., 2002. Anais... Recife: Sociedade Brasileira de Zootecnia, 2002b. p.238-240.

COLOMER-ROCHER, F.; ESPEJO, M.D. Determinación del peso optimo de sacrifício de tos corderos procedentes del cruzamiento Manchega x Rasa Aragonesa en función del sexo. Revista ITEA, n.5, p.219-235, 1972 .

CROUSE, J.D.; BUSBOOM, J.R.; FIELD, R.A. et al. The effects of breed, diet, sex, location and slaughter weight on lamb growth, carcass composition and meat flavor. Journal of Animal Science, v.53, n.2, p.376-386, 1981

DRANSFIELD, E.; NUTE, G.R.; HOGG, B.W. et al. Carcass and eating quality of ram, castrated ram and ewe lambs. Animal Production, v.50, n.3, p.291-299, 1990.

FELÍCIO, P.E. Qualidade da carne bovina: características físicas e organolépticas. In: REUNIÃO ANUAL DA SOCIEDADE BRASILEIRA DE ZOOTECNIA, 36., 1999, Porto Alegre. Anais... Porto Alegre: Sociedade Brasileira de Zootecnia, 1999. p.91-93.

FITZGERALD, J.; MICHEL, F.; BUTLER, W.R. Growth and sexual maturation in ewes: The role of photoperiod, diet and temperature on growth rate and the control of prolactin, thyroxine and luteinizing hormone secretion. Journal of Animal Science, v.55, n.6, p.1431-1440, 1982

FORBES, J.M.; EL SHAHAT, A.A.; JONES, R. et al. The effect of daylenght on the growth of lambs 1 . Comparisons of Sex, level of feeding, shearing and breed of sire. Animal Production, v.29, n.1, p.33-42, 1979

GARCIA, C.A.; SILVA SOBRINHO, A.G. Desempenho e características das carcaças de ovinos alimentados com resíduo de panificação "biscoito" In: REUNÃO ANUAL DA SOCIEDADE BRASILEIRA DE ZOOTECNIA, 35., 1998, Botucatu. Anais... Botucatu: Sociedade Brasileira de Zootecnia, 1998. p.29.

GARCIA, C.A.; ROÇA, R.O.; LEMOS NETO, M.J. et al. Efeito da substituição do milho pela semente de sorgo vassoura (Sorghum bicolor moench) na análise sensorial e química da carne de cordeiros confinados In: REUNIÃO ANUAL DA SOCIEDADE BRASILEIRA DE ZOOTECNIA, 36., 1999, Porto Alegre, Anais... Porto Alegre: Sociedade Brasileira de Zootecnia, 1999.

HOFFMAN, L.C.; MULLER, M.; ClOETE, S.W.P. et al. Comparison of six crossbred lamb types: sensory, physical and nutritional meat quality characteristics. Meat Science, v.65, n.2, p.1265-1274, 2003.

HONIKEL, K.O. Reference methods for the assessment of physical characteristics of meat. Meat Science, v.49, n.4, p.447-457, 1998

KELESTIMUR, H. The physiological effects of castration and testosterone on growth, levels of some blood metabolites and carcass characters in white Karanttian ram lambs. Journal of Animal Science, v.9, n.1, p.166-180, 1985.

LEMOS NETO, M.J. Caracteres qualitativos da carne de cordeiros da raça Corriedale e mestiços Ile de France $x$ Corriedale, terminados em confinamento. Botucatu, Universidade Estadual Paulista, 1997. 84p. Dissertação (Mestrado em Zootecnia) - Universidade Estadual Paulista, 1997.

MACEDO, F.A.F. Desempenho e características de carcaça de cordeiros Corriedale e Bergamácia $x$ Corriedale $e$ Hampshire Down x Corriedale, terminados em pastagem e confinamento. Botucatu: Universidade Estadual Paulista, 1998. 106p. Tese (Doutorado em Zootecnia) - Universidade Estadual Paulista, 1998
MALPAUX, B.; VIGUIE, C.; THIERY, J.C. et al. Photoperiodic control of reproduction. Production Animal, v.9, n.1, p.923, 1996.

MONTENEGRO, R.L.; SIQUEIRA, E.R. Influência do fotoperíodo no desempenho de cordeiros terminados em confinamento: velocidade de crescimento, características da carcaça, análise hormonal e morfologia do epitélio intestinal. Ciência Rural, v.32, n.6, p.21-31, 2001

NATIONAL RESEARCH COUNCIL - NRC. Nutrient requirements of sheep. 6.ed. Washington, D.C.: National Academy Press, 1985. 99p.

OSÓRIO, J.C.S.; OSÓRIO, M.T.M.; JARDIM, P.C. et al. Composição regional e tecidual em cordeiros Corriedale não castrados e castrados. In: REUNIÃO ANUAL DA SOCIEDADE BRASILEIRA DE ZOOTECnIA, 36., 1999, Porto Alegre. Anais... Porto Alegre: Sociedade Brasileira de Zootecnia, 1999, p.86-89.

PRADO, O.V.; PEREZ, J.R.O.; BRESSAN, M.C. et al. Influência do peso ao abate sobre os parâmetros físico-químicos da carne de cordeiro das raças Santa Inês e Bergamácia mantidos em confinamento. In: REUNIÃO ANUAL DA SOCIEDADE BRASILEIRA DE ZOOTECNIA, 36., 1999, Porto Alegre. Anais... Porto Alegre: Sociedade Brasileira de Zootecnia, 1999. p.79-81.

PRICE, J.F.; SCHWEIGERT, B.S. Calidad de la carne. In: Ciencia de la carne y de los productos cárnicos. Zaragoza: Acribia, 1976. p.379-412.

RIBEIRO, E.L.A.; ROCHA, M.A.; MIZUBUT1, I.Y. et al. Desempenho de borregos Ile de France não castrados ou castrados e Hampshire Down castrados abatidos aos 12 meses de idade. In: REUNIÃO ANUAL DA SOCIEDADE BRASILEIRA DE ZOOTECNIA, 35., 1998, Botucatu. Anais... Botucatu: Sociedade Brasileira de Zootecnia, 1998. p.709.

ROÇA, R.O. Desenvolvimento de fiambres com carne de frango. Campinas: Universidade Estadual de Campinas, 1986. 183p. Dissertação (Mestrado em Tecnologia de Alimentos) Universidade Estadual de Campinas, 1986.

ROWE, A. Composição química da carne de cordeiros de diferentes grupos genéticos terminados em pastagem ou confinamento. Maringá: Universidade Estadual de Maringá, 1998. 85p. Dissertação (Mestrado em Química) - Universidade Estadual de Maringá, 1988

SÁ, J.L.; SIQUEIRA, E.R.; OTTO de SÁ, C. et al. Características de carcaça de cordeiros Hampshire Down e Santa Inês sob diferentes fotoperíodos. Pesquisa Agropecuária Brasileira, v.40, n.3, p.289-297, 2005.

SANTOS, C.L.; PÉREZ, J.R.O.; BRESSAN, M.C. et al. Componentes químicos da costela/fralda de cordeiros Santa Inês e Bergamácia. In: REUNIÃO ANUAL DA SOCIEDADE BRASILEIRA DE ZOOTECNIA, 40., 2003, Santa Maria. Anais... Santa Maria: Sociedade Brasileira de Zootecnia, 2003. (CD-ROM), cód 6-328.

SANTOS, C.L.; PÉREZ, J.R.O.; BRESSAN, M.C. et al. Determinação de componentes químicos de cortes da carcaça de cordeiros Santa Inês. In: REUNIÃO ANUAL DA SOCIEDADE BRASILEIRA DE ZOOTECNIA, 39., 2002, Recife. Anais... Recife: Sociedade Brasileira de Zootecnia, 2002. (CD-ROM), cód 6-256.

SAÑUDO, C. Factors affecting carcass and meat quality in lambs. In: REUNIÃO ANUAL DA SOCIEDADE BRASILEIRA DE ZOOTECNIA, 39., 2002, Recife. Anais... Recife: Sociedade Brasileira de Zootecnia, 2002. (CD-ROM), cód 1-2.

SAÑUDO, C. La calidad organoléptica de la carne con especial referencia a la especie ovina: factores que la determinan, métodos de medida y causes de variación. Zaragoza: Instituto Nacional de Investigación y Tecnología Agraria y Alimentaria, 1992. $117 \mathrm{p}$.

SARTI, D.M. Caratteristiche chimiche della came di agnelli Appenninici in funzione dell'eta di macellazione e del livello nutritivo. Zootecnia Nutrizione Animale, v.19, n.1, p.103-112, 1993. 
STATISTICAL ANALYSIS SYSTEM - SAS. User's procedures guide. Version 6. 4.ed. v.1-2, Cary: 1989. 1686p.

SCHANBACHER B.D. Hormonal and photoperiodic control of growth. Manipulation of growth in farm animals. In: ROCHE, J.F.; O'CAllaghan, D. (Eds.) The Netherlands. London: Elsevier Applied Science, 1984. p.275-286.

SCHANBACHER B.D.; CROUSE J.D. Growth and perfomance of growing-finishing lambs exposed to long or shot photoperiods. Journal of Animal Science, v.51, n.4, p.943-48, 1980.

SILVA SOBRINHO, A.G. Aspectos quantitativos e qualitativos da produção de carne ovina. In: REUNIÃO ANUAL DA SOCIEDADE BRASILEIRA DE ZOOTECNIA, 38., 2001, Piracicaba. Anais... Piracicaba: Sociedade Brasileira de Zootecnia, 2001. p.46-53.

SIQUEIRA, E.R. Sistemas de confinamento de ovinos para corte do sudeste do Brasil. In: SIMPÓSIO INTERNACIONAL SOBRE CAPRINOS E OVINOS DE CORTE, 1., 2000, João Pessoa. Anais... João Pessoa: 2000. p.107-117.

SIQUEIRA, E.R.; AMARANTE, A.F.T.; FERNANDES, S. Estudo comparativo da recria de cordeiros em confinamento e pastagens. Revista de Veterinária e Zootecnia, v.5, n.1, p.17-28, 1993.

SNEDECOR, G.W.; COCHRAN, W.G. Statistical methods. 8.ed. Ames: Iowa State University Press, 1989. 564p.

SOLOMON, M.B.; LINCHAR, G.P.; ONO, K. et al. Lipid composition of muscle and adipose tissue from crossbred ram, wether and cryptorchid lambs. Journal of Animal Science, v.68, n.1, p.137-142, 1990.

VOISEY, P.W. Engineering assessment and critique of instruments used for meat tenderness evaluation. Journal of Textural Studies, v.7, n.1, p.11-48, 1976.

Recebido: 01/11/05 Aprovado: 28/03/06 